\title{
Video-assisted thoracoscopic surgery under non- intubated spontaneous breathing anesthesia using laryngeal mask
}

\author{
Premjithlal Bhaskaran ${ }^{1,2^{*}}$, Antonios Katsipoulakis ${ }^{3}$, Francesca Caliandro ${ }^{1}$, Niall McGonigle ${ }^{1}$, Nikolaos Anastasiou ${ }^{1,3}$ \\ From World Society of Cardiothoracic Surgeons 25th Anniversary Congress, Edinburgh \\ Edinburgh, UK. 19-22 September 2015
}

\section{Background/Introduction}

During the past 20 years, video-assisted thoracoscopic surgery (VATS) has been an important minimally invasive tool. In order to further reduce its invasiveness, non-intubated spontaneous breathing general anesthesia via a laryngeal mask (LMA) was used in a variety of thoracic procedures. The objective of this study is to evaluate the safety and feasibility of this advantageous technique.

\section{Aims/Objectives}

From March 2013 till now, 23 patients with lung or pleural disease were managed by VATS under spontaneous breathing general anesthesia with LMA without using muscle relaxants.

\section{Method}

\section{Results}

The mean operative time was 40 minutes (range, 15-90 minutes). The values of lower oxygen saturation and peak end-tidal carbon dioxide tension were $95 \%$ and $50 \mathrm{mmHg}$, respectively. No mask displacement occurred. No conversion to endotracheal anesthesia was required, whereas one patient required conversion to mini thoracotomy. The level of technical feasibility was excellent in 12 cases and good in 11 cases. Mortality as well as morbidity rates were zero. Mean postoperative stay was 2.6 days.

\section{Discussion/Conclusion}

It seems that VATS is safe and feasible under non-intubated spontaneous breathing anesthesia with LMA. A confident

${ }^{1}$ Department of Cardiothoracic Surgery, Harefield Hospital, Middlesex UB9

6JH, Royal Brompton \& Harefield NHS Foundation Trust, UK

Full list of author information is available at the end of the article
Table 1 Clinical characteristics of the patients

\begin{tabular}{lc}
\hline Mean Age (years) & 53.5 \\
Age Range (years) & $20-87$ \\
Male/Female & $9 / 7$ \\
Weight (kg) & $56-100$ \\
BMI (kg/m2) & $<30$ \\
ASA class & $1-I 1$ \\
\hline
\end{tabular}

Table 2 Type of LMA used

\begin{tabular}{lc}
\hline Type of LMA & Patients \\
\hline LMA ProSeal & 21 \\
LMA Fastrach & 2 \\
\hline
\end{tabular}

Table 3 Type of thoracic procedure

\begin{tabular}{lc}
\hline Procedure & Patients \\
\hline Pleural biopsy & 2 \\
Lung biopsy & 4 \\
Pulmonary nodule excision & 4 \\
Pericardial window & 3 \\
Multiloculated empyema debridement & 2 \\
Pneumothorax & 8 \\
\hline
\end{tabular}

manipulation of lung parenchyma is allowed preventing from cough, pain, or panic attack described for awake epidural anesthesia, as well as avoiding the risks of tracheal intubation and mechanical ventilation.

\section{Authors' details}

'Department of Cardiothoracic Surgery, Harefield Hospital, Middlesex UB9 $6 \mathrm{JH}$, Royal Brompton \& Harefield NHS Foundation Trust, UK. ${ }^{2}$ Department of Cardiovascular Surgery, Hammersmith Hospital, Imperial College, London W12 OHS, UK. ${ }^{3}$ Departments of Thoracic Surgery, Anesthesia and Postoperative Intensive Care, General Oncology Hospital of Kifissia "Agioi Anargyroi", Kaliftaki, P.C. 14564, Kifissia, Athens, Greece. 
Submit your next manuscript to BioMed Central and take full advantage of:

- Convenient online submission

- Thorough peer review

- No space constraints or color figure charges

- Immediate publication on acceptance

- Inclusion in PubMed, CAS, Scopus and Google Scholar

- Research which is freely available for redistribution

Submit your manuscript at www.biomedcentral.com/submit 